\title{
Induction of interleukin-8 in human retinal pigment epithelial cells after denuding injury
}

\author{
Ayako Yoshida, Susan G Elner, Zong-Mei Bian, Victor M Elner
}

\begin{abstract}
Aim-To determine interleukin 8 (IL-8) and monocyte chemoattractant protein 1 (MCP-1) expression in response to mechanical injury in human retinal pigment epithelial (HRPE) cells.

Methods-Enzyme linked immunosorbent assay (ELISA) was performed to determine IL-8 and MCP-1 secretion by HRPE cells after mechanical denudation. IL-8 and MCP-1 mRNA expression by HRPE cells was assessed using semiquantitative RT-PCR. The effects of immunosuppressive drugs, dexamethasone (DEX) and cyclosporin A (CSA), as well as immunosuppressive cytokines, interleukin 4 (IL-4), interleukin 10 (IL-10), and interleukin 13 (IL-13), on chemokine expression in HRPE cells after denuding injury were analysed.

Results-Mechanical injury induced HRPE IL-8 mRNA and IL-8 secretion. Although MCP-1 mRNA was enhanced slightly after denuding injury, MCP-1 secretion was not increased. DEX and CSA inhibited HRPE chemokine expression after injury. IL-4 and IL-13 enhanced IL-8 and MCP-1 production by HRPE cells after injury while IL-10 had no effect.

Conclusions-These results suggest that IL-8 may be involved in retinal inflammatory responses to injury and that DEX and/or CSA treatment may help control the inflammatory components of retinal diseases such as proliferative vitreoretinopathy.

(Br F Ophthalmol 2001;85:872-876)
\end{abstract}

Department of

Ophthalmology,

University of

Michigan, Ann Arbor,

MI, USA

A Yoshida

S G Elner

Z M Bian

V M Elner

Department of

Pathology

V M Elner

Correspondence to:

Victor M Elner, MD, PhD,

Department of

Ophthalmology, WK Kellogg

Eye Center, University of

Michigan, 1000 Wall Street,

Ann Arbor, MI 48105, USA

velner@umich.edu

Accepted for publication

8 February 2001
Human retinal pigment epithelial (HRPE) cells, situated between the neurosensory retina and the choroid, form part of the blood-retinal the pathogenesis of proliferative vitreoretinopathy (PVR). ${ }^{1}$ PVR is a pathological intraocular wound healing response after retinal detachment, ocular perforation, or intraocular surgery. ${ }^{1}$ Important factors for initiation of PVR are mechanical dispersal of HRPE cells, breakdown of the blood-retinal barrier, and infiltration of the vitreous and subretinal space with inflammatory cells. ${ }^{23}$ HRPE cells migrate and proliferate to form contractile membranes, frequently containing inflammatory cells and often leading to tractional retinal detachment and visual loss, suggesting that HRPE cells might play a central part in the initiation and propagation of PVR as an aberrant, inflammation driven wound healing response. However, barrier and are thought to be a key cell type in how HRPE cells may initially respond to mechanical injury remains largely unknown.

Inflammatory cells including monocytes/ macrophages, neutrophils, and lymphocytes appear to be integral to the development of PVR. ${ }^{145}$ We previously reported that interleukin 8 (IL-8) and monocyte chemoattractant protein 1 (MCP-1) were two chemokines responsible for the majority of HRPE derived leucocyte chemotactic activity that is induced by interleukin $1 \beta$ (IL- $1 \beta$ ), tumour necrosis factor- $\alpha$ (TNF- $\alpha$ ), and interferon- $\gamma \cdot{ }^{6}{ }^{7}$ Chemokines have been divided mainly into two subgroups based on the juxtaposition of the first two cysteine residues in their amino acid sequences. IL-8, a member of the C-X-C family, is primarily chemotactic for neutrophils and eosinophils while MCP-1, a C-C chemokine, attracts and stimulates monocytes and lymphocytes. ${ }^{8}$ We have shown that IL-8 and MCP-1 are present in eyes from patients with PVR. ${ }^{9}$ Therefore, chemokines produced by HRPE cells are likely to be involved in recruiting inflammatory cells in PVR. Mechanical stresses of stretching and detachment of pulmonary alveolar, bronchial, and intestinal epithelial cells induces IL-8 production. ${ }^{10-12}$ In light of these facts, we hypothesise that HRPE cells may produce chemokines, particularly IL-8, in response to mechanical injury following retinal detachment, leading to leucocyte recruitment in the initiation and propagation of PVR.

In this study, we examined HRPE chemokine expression in response to mechanical denuding injury. In addition, we tested whether mechanical injury induced chemokine expression could be reduced by the immunosuppressive drugs, dexamethasone (DEX) and cyclosporin A (CSA), as well as potent anti-inflammatory cytokines, interleukin 4 (IL4), interleukin 10 (IL-10), and interleukin 13 (IL-13). Strategies aimed at modulating retinal derived chemokines may be helpful in the control of clinical PVR.

\section{Materials and methods}

HRPE CELL CULTURE

HRPE cells were isolated from donor eyes within 24 hours of death as previously described in accordance with the Helsinki agreement. ${ }^{6}$ In brief, the HRPE cells were trypsinised $(0.25 \%)$ from Bruch's membrane into serum free Dulbecco's modified essential medium (DMEM) containing $0.02 \mathrm{mg} / \mathrm{ml}$ DNase I. Isolated HRPE cells were seeded into Falcon Primaria flasks in DMEM containing $15 \%$ fetal bovine serum, penicillin G (100 $\mathrm{U} / \mathrm{ml})$, streptomycin $(100 \mathrm{mg} / \mathrm{ml})$, and amphotericin B (2.5 mg/ml) (Gibco Inc, Grand 
Island, NY, USA). The HRPE monolayers exhibited uniform immunohistochemical staining for fibronectin, laminin, and type IV collagen in a chicken wire distribution, characteristic for these epithelial cells. Cells were subcultured into six well plates and four chamber culture slides for enzyme linked immunosorbent assay (ELISA) and immunocytochemistry, respectively, grown to confluency, and used for experiments.

DAMAGING OF THE MONOLAYER OF HRPE CELLS Before experiments, confluent monolayers of HRPE cells were incubated in serum free DMEM for 24 hours. Cells were preincubated with DEX $\left(10^{-6} \mathrm{M}\right)$ or CSA $(30 \mathrm{ng} / \mathrm{ml})$ for 1 hour or recombinant (r) IL-4, rIL-10, or rIL-13 (R\&D Systems, Minneapolis, MN, USA) for 24 hours, damaged with a plastic comb as previously described, ${ }^{13}$ and then washed with DMEM. HRPE cells migrated from the edge of the wound and repaired the denuded space by 72 hours. We selected the preincubation time above because 1 hour preincubation of DEX and CSA was enough to reduce chemokine production in experiments in previous reports ${ }^{14}{ }^{15}$ and because we previously found that 24 hours of preincubation was needed to inhibit HRPE HLA-DR expression by IL-10. ${ }^{16}$ After experimental incubations, culture media were collected, and stored at $-70^{\circ} \mathrm{C}$ until ELISA was performed.

\section{ENZYME LINKED IMMUNOSORBENT ASSAY}

ELISA was performed on serial dilution of HRPE supernatants. Antigenic IL-8 and MCP-1 were quantitated using a double ligand ELISA method as described previously. ${ }^{9}$

SEMIQUANTITATIVE REVERSE TRANSCRIPTION PCR Synthetic oligonucleotide primers based on the cDNA sequences of human IL-8, MCP-1, and $\beta$-actin were prepared: IL-8, 5'-AAGCTGGC CGTGGCTCTCTTG-3' and 5'-AGCCCTC TTCAAAAACTTCTC-3'; MCP-1, 5'-GCTC ATAGCAGCCACCTTCATTC-3' and 5'GTCTTCGGAGTTTGGGTTTGC-3'; and $\beta$-actin, 5'-GTGGGGCGCCCCAGGCA CCA-3' and 5'-CTCCTTAATGTCACGC ACGATTTC-3'. Polymerase chain reaction (PCR) was carried out in a semiquantitative manner, essentially as previously described. ${ }^{17}$ First strand cDNA was synthesised using Moloney murine leukaemia virus reverse transcriptase (Gibco-BRL, Gaithersburg, MD, USA). RNA, $1 \mu \mathrm{g}$, was denatured at $65^{\circ} \mathrm{C}$ for


Figure 1 IL-8 and MCP-1 secretion by HRPE cells after denuding injury. HRPE cells were damaged with a plastic comb. After experimental incubations for 24 hours, IL-8 and $M C P-1$ in culture media were measured using ELISA. ${ }^{\star} p<0.05$, compared with control.
10 minutes and added to the reverse transcription mixture, as indicated by the manufacturer. After incubation at $37^{\circ} \mathrm{C}$ for 1 hour, cDNA was then subjected to PCR. Linearity range of the reaction was determined running 15-35 cycles. DNA was denatured for 5 minutes at $94^{\circ} \mathrm{C}$, followed by 28,26 , and 20 PCR cycles for IL-8, MCP-1, and $\beta$-actin respectively. Each cycle included a 1 minute denaturation at $94^{\circ} \mathrm{C}$, a 1 minute primer annealing at $65^{\circ} \mathrm{C}$, and a 2 minute polymerisation at $72^{\circ} \mathrm{C}$. Each reverse transcription-PCR reaction mixture was analysed by electrophoresis on a $2 \%$ agarose gel and stained with ethidium bromide. The intensity of the ethidium bromide luminescence was measured by an image sensor with a computer controlled display.

\section{IMMUNOCYTOCHEMISTRY}

Immunocytochemical staining for HRPE cells IL-8 was performed as previously described. ${ }^{78}$ HRPE cells were fixed with $4 \%$ paraformaldehyde. HRPE cells were overlaid with blocking serum (Vector Laboratories, Inc, Burlingame CA, USA) for 20 minutes and incubated with goat polyclonal anti-human IL-8 antibody (Santa Cruz, CA, USA) at $4^{\circ} \mathrm{C}$ overnight, followed by incubation with biotinylated antigoat antibody (Vector Laboratories, Inc) for 50 minutes, and streptavidin-biotinylated horseradish peroxidase complexes (Vector Laboratories, Inc) for 30 minutes. Reaction product was developed in buffer containing 3-amino-9ethylcarbazole $(5 \mathrm{mg} / \mathrm{ml})$ and $0.01 \% \mathrm{H}_{2} \mathrm{O}_{2}$ yielding granular, red-brown, reaction product. Negative controls using goat serum as primary antibody did not yield observable immunocytochemical reaction product.

STATISTICAL ANALYSIS

Individual experiments were performed in triplicate three times on three different HRPE cells from different donors who were 37,51 , and 60 years old. Values for protein of supernatant are expressed as a final concentration per $5 \times 10^{5}$ cells. Data are expressed as mean (SEM)). The data in the graphs are the combined results of the three experiments. Analysis of variance (ANOVA) with a post hoc analysis (Scheff multiple comparison test) and Student's $t$ test were used to determine differences between multiple and two group, respectively; $\mathrm{p}$ values $<0.05$ were considered to be statistically significant.

\section{Results}

Denuding injury induced IL-8 secretion, but not MCP-1 secretion by the HRPE cultures (Fig 1). Immunocytochemical analysis revealed that the expression of IL- 8 protein was observed in HRPE cells at the edge of the scrape and motile HRPE cells (Fig 2). Slight staining for immunoreactive IL-8 was detected in some HRPE cells untouched by the comb. DEX and CSA inhibited IL-8 secretion induced by denuding injury (Fig 3). MCP-1 secretion by injured and uninjured HRPE cultures was inhibited by DEX and CSA (Fig 3). Consistent with ELISA data, denuding injury induced steady state IL-8 mRNA (Fig 4A, 4B). 
A



B

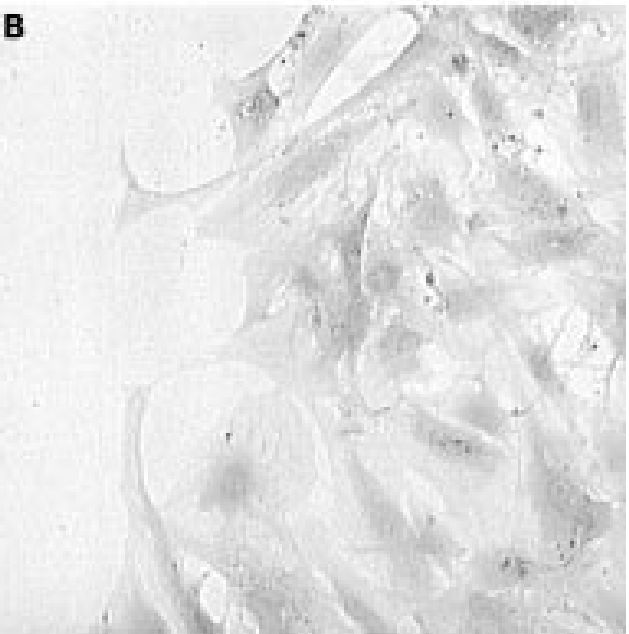

Figure 2 Immunocytochemical staining for IL-8 of HRPE cells 12 hours after denuding injury. HRPE cells were damaged and incubated for 12 hours. Cells were fixed and incubated with anti-IL-8 antibody $(A)$ or goat serum (B). Bound antibodies were detected by a conventional avidin-biotin-peroxidase. (A) IL-8 is prominently detected mainly in HRPE cells at the edge of the scrape and motile HRPE cells. Slight staining for immunoreactive IL-8 is detected in some cells untouched by the comb. (B) No immunoreactivity is observed. Scale bar $=100 \mu \mathrm{m}$.

MCP-1 mRNA was slightly enhanced by denuding injury, even though MCP-1 secretion was not increased. DEX and CSA reduced denuding injury induced steady state IL-8 mRNA expression and MCP- 1 mRNA expression of injured and uninjured HRPE cultures.

We next investigated the effects of immunosuppressive cytokines, IL-4, IL-10, and IL-13, on injured HRPE chemokine expression.
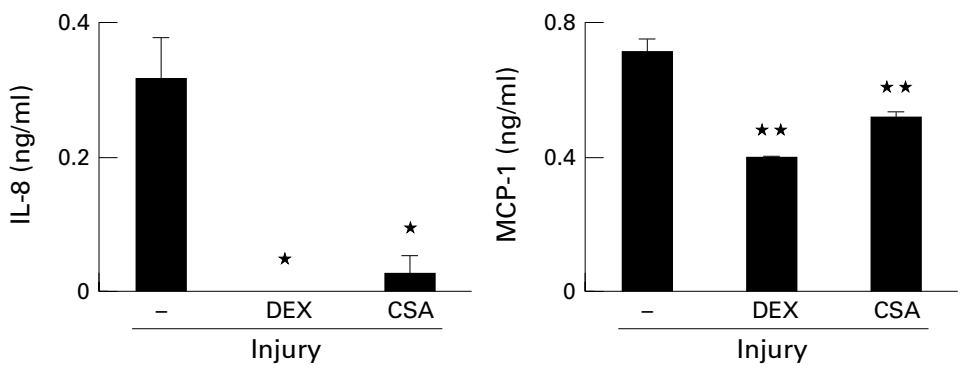

Figure 3 The inhibition of dexamethasone (DEX) and cyclosporin A (CSA) on HRPE IL-8 and MCP-1 secretion after denuding injury. HRPE cells were preincubated with DEX or CSA for 1 hour and damaged. Culture media were assayed using ELISA. ${ }^{\star} p<0.05 ;{ }^{\star \star} p$ $<0.01$, compared with supernatant from injured HRPE cells without agents $(-)$.
Denuding injury induced HRPE IL-8 production was enhanced by IL- 4 and IL-13, which also enhanced MCP-1 secretion by injured HRPE cultures (Fig 5). IL-10 had no significant effects on chemokine secretion. IL-8 and MCP-1 mRNA expression in injured HRPE cultures was enhanced by IL-4 and IL-13 (Fig $6 \mathrm{~A}, 6 \mathrm{~B})$. IL-10 had no effects on injured HRPE chemokine mRNA expression.

\section{Discussion}

In PVR, mechanical injury from non-surgical and surgical trauma damages and disperses HRPE cells. This may lead membrane formation and contraction characteristic of PVR. Inflammatory cells attracted into the vitreous and subretinal space may appear to be essential to evolving PVR. ${ }^{4}$ Therefore, mechanisms recruiting and activating selective inflammatory cells, such as the regulated secretion of chemokines by resident, injured retinal cells, may be important in the pathogenesis of PVR. Among retinal cells, HRPE cells are anatomically well positioned and functionally able to participate in chemokine secretion.

In general wound healing, chemokines have the unique potential to activate and selectively guide various leucocyte subtypes to specific microanatomical sites of wound during different phases of tissue repair. Initially, neutrophils accumulate in the damaged tissue before monocyte/macrophage and lymphocyte infiltration. Accumulating leucocytes produce a battery of proinflammatory cytokines and growth factors which are thought to be involved in development of PVR. ${ }^{918}$ In our study, we found that mechanical injury triggers HRPE IL-8 production that may lead to neutrophil recruitment in the retinal wound healing response. Accordingly, IL-8 has been detected in subretinal fluid from the eyes with retinal detachment and in the vitreous of eyes with PVR ${ }^{9} 19$ and neutrophils were found in the subretinal space and retina in the experimental retinal detachment. ${ }^{20}$ Although IL- 8 could be produced by many cells including retinal glial cells, endothelial cells, and leucocytes, HRPE cells may be a main source of IL-8. IL- 8 was detected in the HRPE cells at the edge of the scrape and in motile cells by immunocytochemistry, indicating these cells are the main sources of IL-8 in our culture model. Activated $\mathrm{NF}-\kappa \mathrm{B}$, an important transcription factor for IL-8, has been demonstrated in vascular endothelial cells at the wound edge and cells replicating after denuding injury, ${ }^{21}$ supporting the notion that cells adjacent to injury may produce IL-8. There is increasing evidence concerning the intracellular responses to mechanical stress, and including IL-8 secretion in responses to mechanical stress. Deformation of cytoskeletal structures has been reported to be important for IL-8 induction in bronchial epithelial cells, ${ }^{12}$ suggesting that cellular deformation caused by injury might induce HRPE IL-8 production. We found slight immunoreactive IL-8 in HRPE cells untouched by the comb, suggesting such cells may also produce low levels of IL-8 in response to juxtacrine or paracrine signals from cells at the edge of the injury. 
A
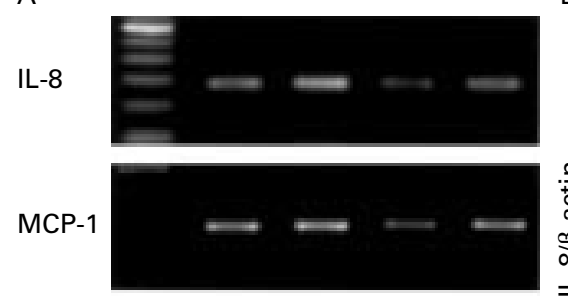

$\beta$-actin



B

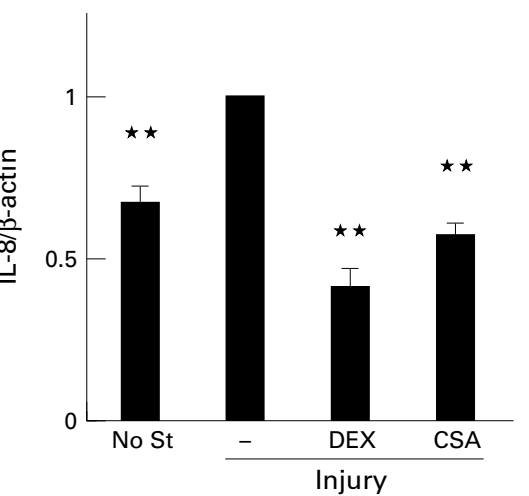

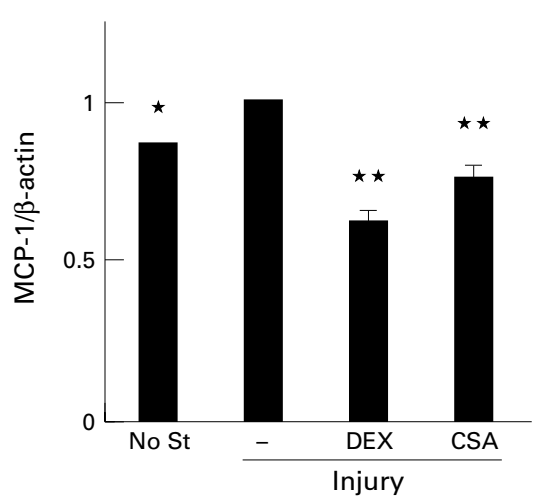

Figure 4 Expression of IL-8, MCP-1, and $\beta$-actin $m R N A$ by HRPE cells. (A) HRPE cells were preincubated with DEX or CSA for 1 hour, and then damaged. After 4 hours, total RNA was extracted from the HRPE cells, and semiquantitative RT-PCR was performed. These representative data are from one of three independent experiments. No St $=$ no stimulant. (B) Results are expressed as a ratio of each PCR product/ $\beta$-actin band density. Values represent means (SEM) ( $n=3) .{ }^{\star} p<0.05 ;{ }^{\star} p<0.01$, compared with $m R N A$ from injured HRPE cells without agents $(-)$. No St $=$ no stimulation.
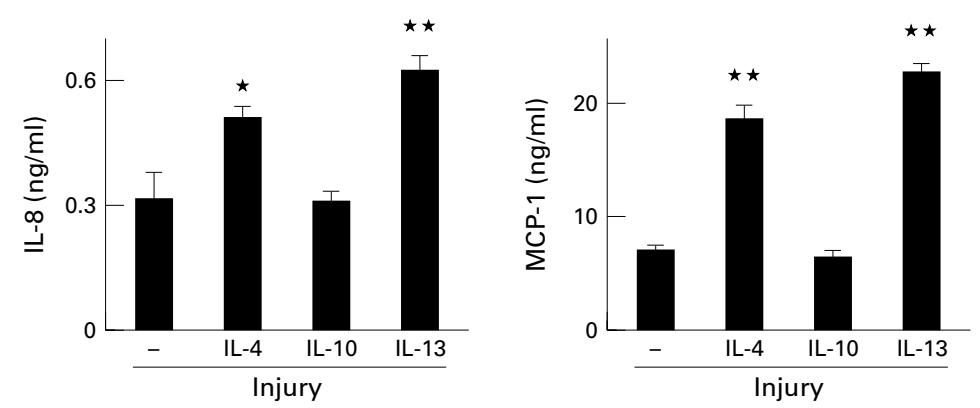

Figure 5 The effects of IL-4, IL-10, and IL-13 on damaged HRPE IL-8 and MCP-1 secretion. HRPE cells were preincubated in serum free DMEM, or the same medium containing $r I L-4$, rIL-10, or rIL-13 for 24 hours, damaged, and incubated for 24 hours. IL-8 and MCP-1 were measured by ELISA. ${ }^{\star} p<0.05 ;{ }^{\star *} p<0.01$, compared with supernatant from HRPE cells without cytokines.

Unstimulated HRPE cell cultures consistently demonstrated basal MCP-1 production whereas no detectable IL-8 levels were observed as we previously reported. ${ }^{72}{ }^{23}$ However, very few monocytes are found in normal retinal tissue. ${ }^{24} \mathrm{MCP}-1$ may cause desensitisation of the monocyte chemotactic response, ${ }^{25} 26$ suggesting that low constitutive levels of MCP released by normal HRPE cells in normal eyes may serve to temper MCP-1 chemotactic responses and not recruit monocytes. Following injury, we could not detect increased HRPE MCP-1 secretion, but MCP-1 mRNA was slightly enhanced, suggesting that there might be suppressive regulation at the posttranscriptional level of $\mathrm{MCP}-1$ production. Although IL-8 is not necessarily the only chemokine induced by injury of HRPE cells, mechanical injury seems to selectively induce chemokines.

In this study, DEX and CSA inhibited injury induced IL-8 production as well as MCP-1 production in control and injured HRPE cultures. Corticosteroids and CSA both appear to impair wound healing. ${ }^{27}{ }^{28}$ Corticosteroids have also been shown to inhibit experimental PVR. ${ }^{29}$ Corticosteroids have numerous antiinflammatory effects including downregulation of prostaglandin, cell adhesion molecules, proinflammatory cytokines, and chemokines. ${ }^{30}$ In particular, corticosteroids inhibit chemokine gene transcription and destabilise chemokine mRNA. ${ }^{31}$ Although CSA is also known to suppress proinflammatory cytokines and chemokines, the mechanisms of mediating
A

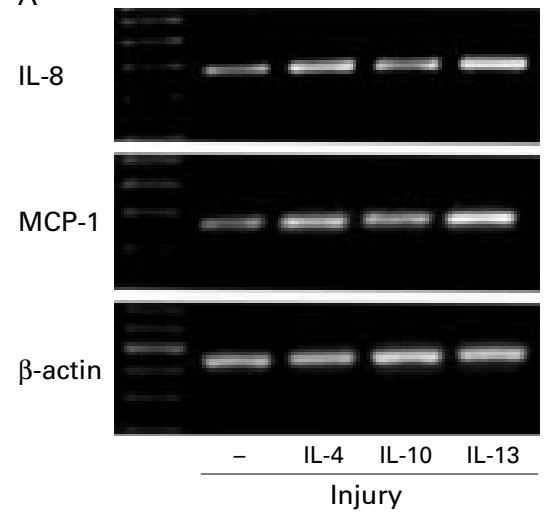

B



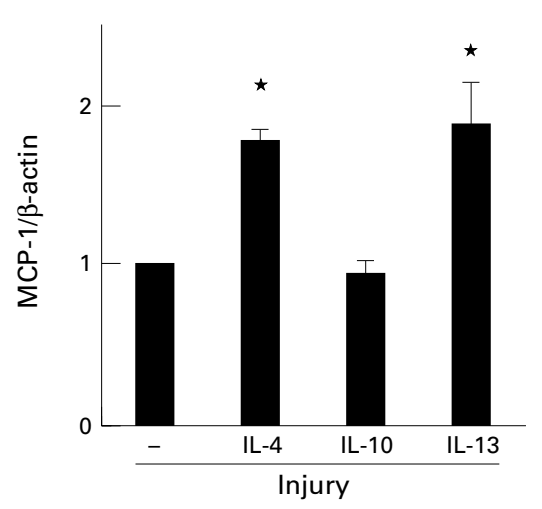

Figure 6 The effects of IL-4, IL-10, and IL-13 on damaged HRPE IL-8 and MCP-1 mRNA expression. (A) HRPE cells were preincubated in serum free DMEM, or the same medium containing rIL-4, rIL-10, or rIL-13 for 24 hours, damaged, and incubated for 4 hours. Total RNA was extracted from the HRPE cell, and semiquantitative RT-PCR was performed. These representative data are from one of three independent experiments. (B) Results are expressed as a ratio of each PCR product/ $\beta$-actin band density. Values represent means (SEM) $(n=3)$. ${ }^{\star} p<0.05$, compared with $m R N A$ from HRPE cells without cytokines (-). 
CSA chemokine inhibition are less well understood. We previously reported that IL- $1 \beta$ induced HRPE IL- 8 and MCP-1 secretion is inhibited by DEX, but not by CSA, while $\mathrm{TNF}-\alpha$ induced chemokine secretion was sensitive to CSA. ${ }^{32}$ Our present data suggest that inhibition of retinal derived chemokines by DEX and/or CSA treatment before surgery may reduce surgically induced inflammation that promotes PVR recurrence by helping to control pathological inflammatory responses of PVR.

IL-4, IL-10, and IL-13 are Th2 cytokines that are considered to be anti-inflammatory since they downregulate proinflammatory cytokine release by activated monocytes in various diseases. ${ }^{33}$ IL-10 and IL-13 have been detected in subretinal fluid from eyes with retinal detachment, but the roles of these cytokines in this setting remain unknown. ${ }^{34} \mathrm{We}$ previously reported that IL-4 induces HRPE IL-8 and MCP-1, but that IL-10 has no significant effects on constitutive or induced IL- 8 and MCP- $1 .{ }^{16}{ }^{35}$ In this study, IL-4 and IL-13 enhanced IL- 8 and MCP-1 secretion by injured HRPE cells, while IL-10 had no such effects. Therefore, these cytokines seem to have potentiate the chemokine inducing effects of injury on HRPE chemokine secretion, in contrast with their effects on monocytes.

In summary, mechanical injury induces HRPE IL-8 production which may trigger recruitment of leucocytes. The IL-8 expression is inhibited by DEX and CSA, but not by Th2 cytokines. These findings may help the prevention and treatment of ocular inflammation by administration of DEX and CSA before surgery. Further in vitro and in vivo studies characterising the roles of chemokines and their regulation may lead to better control of inflammatory components of retinal diseases such as PVR.

This work was supported by NIH grant EY09441, EY007003, and Research to Prevent Blindness-Olga Keith Weiss Award (VME).

1 Jaffe GJ, Roberts WL, Wong HL, et al. Monocyte-induced cytokine expression in cultured human retinal pigment epicytokine expression in cultured human retina

2 Sen HA, Robertson TJ, Conway BP, et al. The role of breakdown of the blood-retinal barrier in cell-injection models of proliferative vitreoretinopathy. Arch Ophthalmol 1988;106: 1291-4.

3 Charteris DG, Lee WR. Multifocal posterior uveitis: clinical and pathological findings. Br f Ophthalmol 1990;74:68893.

4 Charteris DG, Hiscott P, Robey HL, et al. Inflammatory cells in proliferative vitreoretinopathy subretinal membranes. Ophthalmology 1993;100:43-6.

5 Miller B, Miller H, Patterson R, et al. Retinal wound healing. Cellular activity at the vitreoretinal interface. Arch Ophthalmol 1986;104:281-5.

6 Elner VM, Strieter RM, Elner SG, et al. Neutrophil chemoElner VM, Strieter RM, Elner SG, et al. Neutrophil chemo-
tactic factor (IL-8) gene expression by cytokine-treated tactic factor (IL-8) gene expression by cytokine-treated
retinal pigment epithelial cells. Am ₹ Pathol 1990;136:745retina
50 .

7 Elner SG, Strieter RM, Elner VM, et al. Monocyte chemotactic protein gene expression by cytokine-treated human retinal pigment epithelial cells. Lab Invest 1991;64:819-25.

8 Baggiolini M, Dewald B, Moser B. Interleukin-8 and related chemotactic cytokines-CXC and CC chemokines. Adv Immunol 1994;55:97-179.

9 Elner SG, Elner VM, Jaffe GJ, et al. Cytokines in proliferative diabetic retinopathy and proliferative vitreoretinopathy. Curr Eye Res 1995;14:1045-53.
10 Tsuda A, Stringer BK, Mijailovich SM, et al. Alveolar cell stretching in the presence of fibrous particles induces interleukin-8 responses. Am f Respir Cell Mol Biol 1999;21: $455-62$

11 Mahida YR, Makh S, Hyde S, et al. Effect of Clostridium difficile toxin $\mathrm{A}$ on human intestinal epithelial cells: induction of interleukin 8 production and apoptosis after cell detachment. Gut 1996;38:337-47.

12 Shibata Y, Nakamura H, Kato S, et al. Cellular detachment and deformation induce IL- 8 gene expression in human bronchial epithelial cells. F Immunol 1996;156:772-7.

13 Tanaka K, Oda N, Iwasaka C, et al. Induction of Ets-1 in endothelial cells during reendothelialization after denuding injury. F Cell Physiol 1998;176:235-44

14 Pang L, Knox AJ. Synergistic inhibition by beta(2)-agonists and corticosteroids on tumor necrosis factor-alphainduced interleukin-8 release from cultured human airway smooth-muscle cells. Am F Respir Cell Mol Biol 2000;23:7985.

15 Kuhns DB, Young HA, Gallin EK, et al. Ca2+-dependent production and release of IL-8 in human neutrophils. $\mathcal{F}$ Immunol 1998;161:4332-9.

16 Boorstein SM, Elner SG, Bian ZM, et al. Selective IL-10 inhibition of HLA-DR expression in IFN-gammastimulated human retinal pigment epithelial cells. Curr Eye Res 1997;16:547-55.

17 Yoshida A, Yoshida S, Khalil AK, et al. Role of NF-kappaBmediated interleukin-8 expression in intraocular neovascularization. Invest Ophthalmol Vis Sci 1998;39:1097-106.

18 Armstrong D, Augustin AJ, Spengler R et al. Detection of vascular endothelial growth factor and tumor necrosis factor alpha in epiretinal membranes of proliferative diabetic retinopathy, proliferative vitreoretinopathy and macular pucker. Ophthalmologica 1998;212:410-4.

19 Bakunowicz-Lazarczyk A, Moniuszko T, Stankiewicz A, et al. Concentration of selected cytokines in subretinal fluid in patients with retinal detachment (IL-8, TNF-alpha, IFN-gamma). Klin Oczna 1997;99:87-9.

20 Anderson DH, Stern WH, Fisher SK, et al. Retinal detachment in the cat: the pigment epithelial-photoreceptor interface. Invest Ophthalmol Vis Sci 1983;24:906-26.

21 Lindner V, Collins T. Expression of NF-kappa B and I kappa B-alpha by aortic endothelium in an arterial injury model. Am f Pathol 1996;148:427-38.

22 Elner VM, Burnstine MA, Strieter RM, et al. Cellassociated human retinal pigment epithelium interleukin-8 and monocyte chemotactic protein-1: immunochemical and in-situ hybridization analyses. Exp Eye Res 1997;65: and in-siti 9 .

23 Elner VM, Elner SG, Standiford TJ, et al. Interleukin-7 (IL-7) induces retinal pigment epithelial cell MCP-1 and IL-8. Exp Eye Res 1996;63:297-303.

24 Nicolai U, Eckardt C. The occurrence of macrophages in the retina and periretinal tissues in ocular diseases. Ger $\mathcal{F}$ Ophthalmol 1993;2:195-201.

25 Vaddi K, Newton RC. Comparison of biological responses of human monocytes and THP-1 cells to chemokines of the intercrine-beta family. F Leukoc Biol 1994;55:756-62.

26 Proost P, Struyf S, Couvreur M, et al. Posttranslational modifications affect the activity of the human monocyte chemotactic proteins MCP-1 and MCP-2: identification of MCP-2(6-76) as a natural chemokine inhibitor. F Immunol 1998;160:4034-41.

27 Beer HD, Fassler R, Werner S. Glucocorticoid-regulated gene expression during cutaneous wound repair. Vitam Horm 2000;59:217-39.

28 Fishel R, Barbul A, Wasserkrug HL, et al. Cyclosporine A impairs wound healing in rats. F Surg Res 1983;34:572-5.

29 Tano Y, Chandler DB, McCuen BW, et al. Glucocorticosteroid inhibition of intraocular proliferation after injury. $A m \mathcal{F}$ Ophthalmol 1981;91:184-9.

30 Imam AP, Halpern GM. Uses, adverse effects of abuse of corticosteroids. Part I. Allergol Immunopathol (Madr) 1994; 22:250-60.

31 Tobler A, Meier R, Seitz M, et al. Glucocorticoids downregulate gene expression of GM-CSF, NAP-1/IL-8, and IL-6, but not

32 Kurtz RM, Elner VM, Bian ZM, et al. Dexamethasone and cyclosporin A modulation of human retinal pigment epithelial cell monocyte chemotactic protein-1 and interleukin-8. Invest Ophthalmol Vis Sci 1997;38:436-45.

33 Hart PH, Ahern MJ, Smith MD, et al. Regulatory effects of IL-13 on synovial fluid macrophages and blood monocytes from patients with inflammatory arthritis. Clin Exp Iттиnol 1995;99:331-7.

34 Bakunowicz-Lazarczyk A, Mrugacz M, Moniuszko T, et al. Sub-retinal fluid interleukin-10 (Il-10) and interleukin-13 (Il-13) concentration in patients with retinal detachment. Klin Oczna 1999;101:85-7.

35 Bian ZM, Elner SG, Strieter RM, et al. IL-4 potentiates IL-1beta- and TNF-alpha-stimulated IL- 8 and MCP-1 protein production in human retinal pigment epithelial cells. Curr Eye Res 1999;18:349-57. 